\title{
A Comparison of Facilitated and Unfacilitated Administration of the Beliefs about Learning Environments (BALE) Instrument
}

\author{
Eric A. Worch ${ }^{1}$, Emilio Duran ${ }^{1}$, Lena Ballone Duran ${ }^{1}$ and Jacob N. Burgoon ${ }^{2}$ \\ ${ }^{1}$ School of Teaching and Learning, Bowling Green State University, Bowling Green, OH, USA \\ ${ }^{2}$ School of Educational Foundations, Leadership and Policy, Bowling Green State University, Bowling Green, OH, \\ USA \\ Email: eworch@bgsu.edu
}

\begin{abstract}
Science teacher educators need to formatively assess preservice teachers' understanding of the components of an effective science classroom in order to provide remediation before they assume primary responsibility for instruction. The Beliefs About Learning Environments (BALE) instrument has been used in a number of studies to assess knowledge of effective classrooms among preservice teachers, inservice teachers, principals, students, and parents. Interestingly, however, the results showed only small differences in knowledge among the various groups surveyed. We hypothesized that a different means of administration (focus group instead of pencil paper) would produce a stronger relationship between the amount of experience teachers have learning about and teaching inquiry approaches and their knowledge of effective learning environments. We compared the BALE results from a group of senior early childhood majors with those from a group of newly-graduated early childhood majors who participated in a year-long professional development project focused on inquiry science teaching.
\end{abstract}

Key Words: BALE instrument; learning environments; constructivism; teacher beliefs

\section{Introduction}

It has been approximately 15 years since the National Research Council and the American Association for the Advancement of Science produced reports and documents on which many state standards emerged. Recently, a new national reform effort emerged with the release of The Next Generation Science Standards (NGSS Lead States, 2013). The NGSS is based on A Framework for K-12 Science Education: Practices, Crosscutting Concepts, and Core Ideas (NRC, 2012) and is intended to reflect a new vision for science education. The NGSS Appendix A states that "all students no matter what their future education and career path must have a solid $\mathrm{K}-12$ science education in order to be prepared for college, careers, and citizenship."

As revealed in earlier science education reform documents, the principles set forth in the NGSS continue to support positive classroom climate and high levels of student engagement. The NGSS encourage all students to learn and achieve scientific literacy by fostering inquiry-based learning, effective communication, meaning-making across all domains of science, as well as other disciplines, and an environment in which all students can learn and achieve at a high level. The NGSS are rich in content and pedagogy and arranged across disciplines and grades to provide all students an internationally-benchmarked science education.

According to NSTA's position statement, the NGSS are designed to prepare all students for college, career, and citizenship (NSTA, 2013). It states, "Other standards efforts have promoted standards for all students, but we have yet to achieve that goal. NSTA's mission echoes this imperative and we fully support standards that are for all students, not just those destined for careers in science and technology. The demanding and rigorous content in the $N G S S$ can provide a solid foundation for students entering a variety of STEM fields."

However, simply embedding recommendations for student outcomes and teacher knowledge, behaviors and skills (e.g., inquiry-based instructional approaches, formative/summative strategies to assess teaching/learning, valuing the learner's opinions/interests/abilities, stimulating complex thinking) within the NGSS and A Framework for K-2 Science Education is unlikely to promote wide-spread 
change. In the past, teacher beliefs have been shown to play a pivotal role in the degree of implementation of science education reform efforts (Czerniak \& Lumpe, 1996), (Haney, Czerniak \& Lumpe, 1996), (Lumpe, Haney \& Czerniak, 1998). According to Bandura (1997), one of the best indicators of the decisions that individuals make in their lives is their beliefs. In addition, Pajares (1992) asserted that "beliefs are instrumental in defining tasks and selecting the cognitive tools with which to interpret, plan, and make decisions regarding such tasks; hence they play a critical role in defining behavior and organizing knowledge and information" (p. 325). For clarity, beliefs in the current study were defined according to Haney, Czerniak \& Lumpe (2003) as "one's convictions, philosophy, tenets, or opinions about teaching and learning" (p. 367). Teacher beliefs about science teaching are established early in a teacher's life and appear to be stable and resistant to change (Lumpe, Haney \& Czerniak, 2000). Consequently, preservice teachers must believe in the principles of constructivism and inquiry learning in order to have the motivation to create an effective, student-centered environment for learning science through inquiry-based instruction. Based on her study of preservice high school science teachers, Crawford (2002) concluded that "there was evidence that a prospective teacher's set of beliefs about pedagogy, schools, student learning, and the nature of scientific inquiry may have been the overriding factor influencing choice and eventual success in teaching science as inquiry" (p. 635).

Therefore, it is incumbent upon teacher educators to determine if their instruction has shaped students' beliefs toward those espoused by the NGSS framework before student teaching. There have been a few research studies reporting the development and administration of instruments aimed to evaluate teachers' beliefs about effective science classrooms. The following section provides a brief history of one of these instruments and a summary of the research findings.

\section{Background}

The Beliefs About Learning Environments (BALE) instrument was developed by Varrella \& BurryStock (1997) to assess the extent of teachers' constructivist beliefs. Varrella (1997) administered the BALE to 31 middle and high school science teachers participating in the Iowa Scope, Sequence, and Coordination Project, which was funded by the National Science Foundation. The study participants were given the prompt, "What is (your perception of...) the relationship between the students and the teacher in the learning environment" and were instructed to respond by individually writing a one-page essay, providing a concept map, or a list of key points (Varrella, 1997, p. 207). Varrella \& Burry-Stock (1997) developed a scoring rubric organized around four factors based on Berliner's (1988) stage theory of teacher development, which was derived from the work of Dreyfus and Dreyfus (1986): 1) teaching for understanding, 2) context for learning and assessment, 3) valuing the learner as an individual, and 4) seeking the learner's perspective. The factors were further described by 12 belief characteristics $(4,2,4$ and 2 characteristics, respectively by factor). The belief characteristics were each rated on a scale of 1-5, with 5 representing a highly-constructivist response, resulting in a maximum possible score of 60 points.

Haney (personal communication) modified the BALE prompt and rubric (Figure 1) to measure the constructivist beliefs of teachers, administrators, parents/community members, and students. Haney et al., (2003) used the modified prompt, "My perception of the roles and responsibilities of a science or mathematics teacher and his/her students in an effective learning environment is..." to generate openended responses. Respondents were instructed to provide enough detail to enable someone else to accurately visualize the classroom described. The rubric was organized around five factors: 1) teaching for understanding, 2) instructional approach, 3) valuing the learner as an individual, 4) questioning habits, and 5) extension of students' learning. Although somewhat different than those in the Varrella \& Burry-Stock (1997) design, 12 belief characteristics were again used to further describe the five factors (4, 2, 4, 1 and 1 characteristics, respectively by factor), with each rated on a scale of 1-5 and resulting in a maximum score of 60 points.

Haney et al. (2003) found significant differences in the mean overall BALE scores between the four demographic groups $\left(\mathrm{M}_{\text {teachers }}=21.44, \mathrm{M}_{\text {administors }}=21.94, \mathrm{M}_{\text {parents }}=16.35, \mathrm{M}_{\text {students }}=17.38\right)$, with teachers and administrators holding stronger constructivist beliefs than parents/community members. However, student beliefs were not significantly different from other three groups. Compared to the mean overall score for teachers reported by Varrella (1997), the mean overall score for teachers obtained by Haney et al. (2003) was more than 10 points lower. Unfortunately, it is impossible to determine if this difference 
is due to differences in the two populations of teachers or modifications made to the BALE prompt and rubric.

Worch, Pollock, Duran \& Burgoon (2009) used Haney et al.'s (2003) version of the BALE instrument and rubric with 24 inservice teachers (grades 1-3) and nine preservice early childhood teachers (grades PK-3). All of the inservice teachers had at least 10 years of experience. The BALE was administered at the beginning and end of a one-year professional development program. Like Varrella (1997), Worch et al. (2009) found no significant differences between the pre-test and post-test scores for either the preservice teachers $\left(\mathrm{M}_{\text {pre }}=22.1, \mathrm{M}_{\text {post }}=22.6\right)$ or the inservice teachers $\left(\mathrm{M}_{\text {pre }}=21.1, \mathrm{M}_{\text {post }}=22.4\right)$. Moreover, contrary to Berliner's (1988) stage theory of teacher development, there were no significant differences between the novice preservice teachers and highly-experienced inservice teachers on either the pre-test or the post-test administration.

Worch et al. (2009) also conducted focus group interviews with the same group of preservice teachers at the beginning and end of a two-week summer institute. The discussions began by restating the writing prompt, which, at appropriate points in the conversation, was followed bry additional prompts based on the five factors in the BALE rubric. The ensuing discussion among the participants resulted in a much richer description of an effective learning environment than demonstrated by individuallywritten responses to the initial prompt. Furthermore, whereas the written responses to the pre/postadministrations indicated no growth in the preservice teachers' awareness of factors that characterize an effective learning environment, the oral responses did seem to indicate growth; however, these responses were not actually scored. Not only were their responses better developed and morie accurate during the post-institute interview, the participants were less hesitant to express themselves and appeared more confident with their answers. Although the differences between the written and oral responses are suggestive, they should be viewed cautiously because the written responses were completed individually whereas the oral responses were constructed collaboratively.

\title{
My perception of the roles and responsibilities of a science or mathematics teacher and his/her students in an effective learning environment is...".
}

\begin{abstract}
Describe, in DETAIL, the roles and responsibilities enacted by all members of this effective learning environment. (NOTE: Your description should provide enough detail that another person could accurately visualize the same classroom.) Use the backside of this page as needed.
\end{abstract}

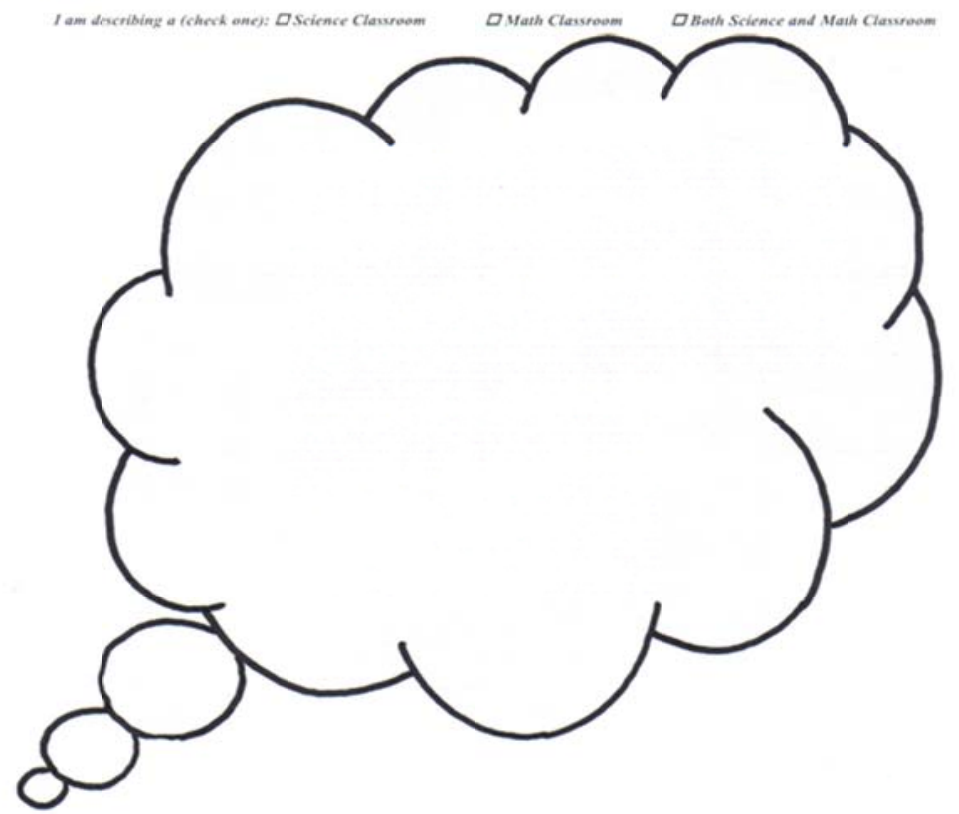

Figure 1. BALE instrument administered during unfacilitated administration. 
In summary, three concerns arise from the results of these studies: 1) no significant differences in BALE scores were found between preservice teachers and inservice teachers (Worch et al., 2009) or even between teachers and students (Haney et al., 2003); 2) neither preservice teachers (Worch et al., 2009) nor inservice teachers (Varrella, 1997; Worch et al., 2009) demonstrated growth in their constructivist beliefs, as measured by the BALE, after a full year of professional development; and 3) the mean overall BALE scores of experienced teachers ranged from $37 \%$ to $54 \%$ of the 60 points possible (Varrella, 1997; Haney et al., 2003; Worch et al., 2009), which is well below what might be considered acceptable performance.

Thus, although the BALE is grounded in Berliner's (1988) widely-cited model of teacher development (e.g., Allen \& Caspergue, 1997; Hattie, 2002; Palmer, Stough \& Burdenski, 2005) and is a valid (Varrella, 1997) and reliable instrument for measuring teachers' beliefs about constructivism and active learning (Varrella, 1997; Haney et al., 2003), its apparent inability to discriminate between novice and experienced teachers or to demonstrate growth in teachers' constructivist beliefs after extensive instructional intervention suggests that the nature of how the BALE is administered and/or the sensitivity of the BALE rubric inadvertently influence the results. In light of the concerns arising out of previous research on the BALE instrument, this study sought to examine the relationship between how the prompt is administered and the quality of preservice teachers' responses to the BALE prompt.

\section{Methods}

Participants were 10 preservice early childhood teachers participating in a one-week summer institute. All participants were female Caucasians between 21 and 23 years of age. The participants were divided into two groups: continuing participants and new participants. The six continuing participants had experienced a two-week professional development session the previous summer, as well as seven 2-hour sessions of professional development to enhance content and pedagogical knowledge using constructivist, inquiry-based learning strategies distributed throughout the previous academic year. All of the continuing participants had completed their student teaching in the spring semester and graduated just before the institute began. The four new participants had just completed science methods, which used and espoused constructivist, inquiry-based practices, and were enrolled in student teaching for the upcoming fall semester. In addition, all participants had completed six semester hours of science content and all of their required professional education coursework.

The BALE was administered independently to both groups of participants using an unfacilitated and a facilitated approach. The unfacilitated administration was administered first. Each group was given a sheet of paper with the following written open-ended prompt: "My perception of the roles and responsibilities of a science or mathematics teacher and his/her students in an effective learning environment is..." (Haney et al., 2003). Participants were asked to cooperate in order to develop an answer they thought fully completed the prompt. They were told that their conversation would be recorded and it would be their oral responses that would be evaluated. To help them keep track of what they had said, the participants were advised to write their responses in the space underneath the prompt and to use the back of the paper if necessary.

During the second administration, both groups participated in a discussion facilitated by one of the researchers. The same prompt that was provided for the first administration was used to initiate the discussion. When an interviewer felt the conversation resulting from the open-ended prompt was drawing to a close, additional prompts were provided to stimulate further discussion, such as, "What kinds of things do you think a teacher should do to promote student learning?" In all, five additional prompts, derived from the BALE rubric (Haney et al., 2003), were used to help participants elaborate upon their response to the initial prompt. These conversations were also recorded.

Audio recordings of the BALE administrations were transcribed, resulting in four sets of transcripts: 1) continuing participants unfacilitated, 2) continuing participants facilitated, 3) new participants unfacilitated, and 4) new participants facilitated. To reduce bias, two scorers independently coded the transcripts by looking for phrases relevant to the characteristics describing each of the five factors in the BALE rubric (Figure 2). For each factor, the combined set of descriptive characteristics was used to assign a subscore on a scale of $1-5$ and then calculate an overall score. Bivariate correlations were performed using SPSS 17.0 to estimate interrater reliability. 


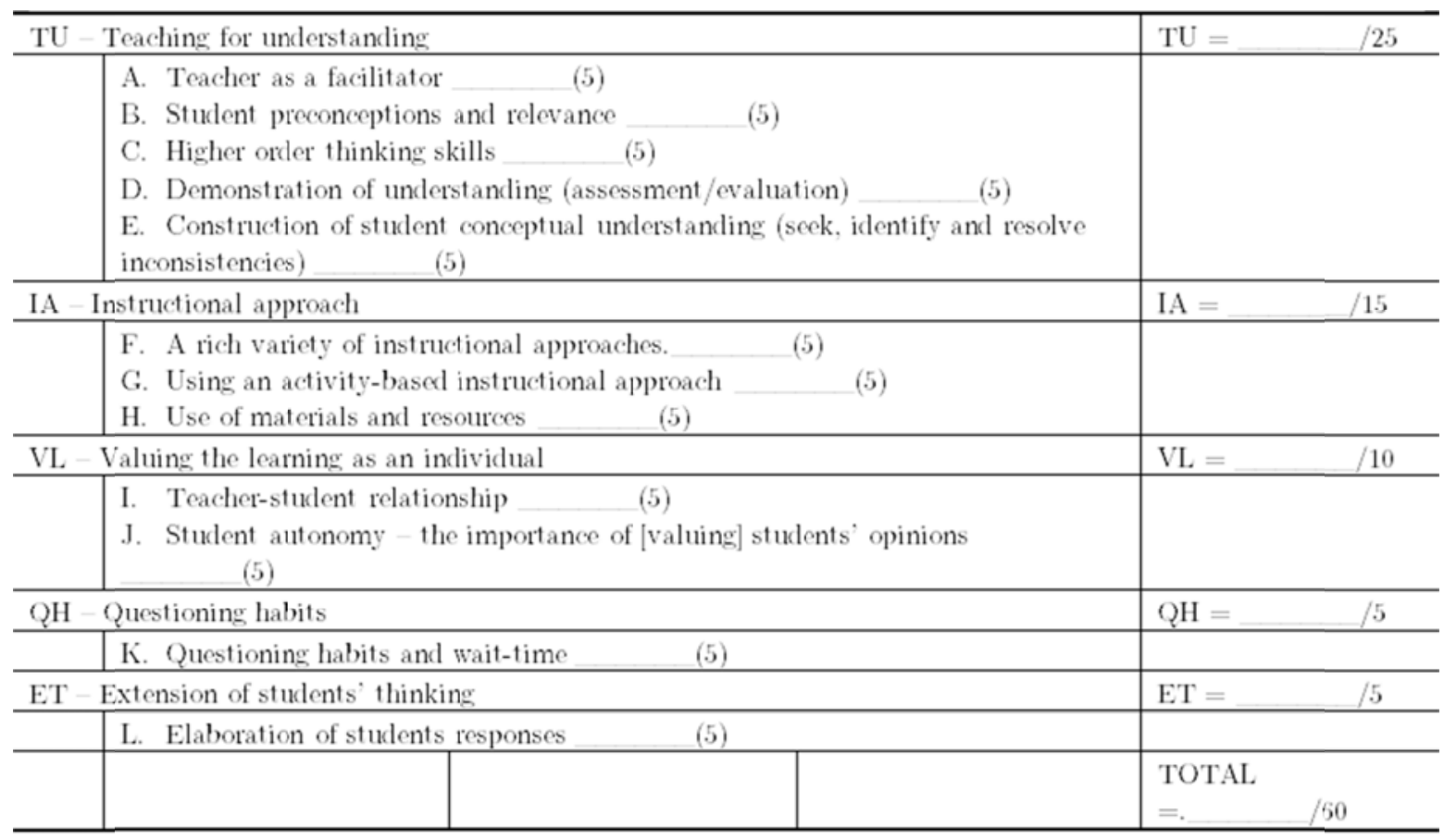

To assign numeric value to the above subtopies (items A-L), use the following guidelines.

\begin{tabular}{l|l}
\hline 5 & Discussed with clarity and linked to other related elements. (elaboration - THEME \\
\hline 4 & Discussed or linked to other related elements (no clarity) - ELABORATION \\
\hline 3 & Identified as a term and/or in a list. CLEARLY DESCRIBED \\
\hline 2 & Alluded to or loosely included, but not clearly stated. ALLUDED \\
\hline 1 & Not identified as a feature of the student and teacher relationship in the learning environment - NOTHING \\
\hline Note & OK to "double count" categories - give credit to 2 different categories for 1 statement. \\
\hline
\end{tabular}

Figure 2. Beliefs about an effective learning environment (BALE) rubric. Retyped from Haney et al. (2003).

\section{$4 \quad$ Results}

\subsection{Interrater Reliability}

The results for interrater reliability are summarized in Table 1. A Pearson's $r$ between .51 and .70 is considered to be moderate agreement between scorers, between .71 and .90 is strong agreement, and between .91 and 1.0 is very strong agreement (LeBreton \& Senter, 2008). For the overall BALE score and all five BALE factors $\left({ }^{1} \mathrm{TU}=\right.$ teaching for understanding; $\mathrm{IA}=$ instructional approach; $\mathrm{VL}=$ valuing the learning as an individual; $\mathrm{QH}=$ questioning habits; ET = extension of students' thinking), Pearson's $r$ was greater than .91. Hence, interrater reliability was sufficiently high to analyze data from both scorers as a single data set.

Table 1. Interrater reliability for bale factor subscores and overall BALE score.

\begin{tabular}{c|c|c|c|c|c|c}
\hline & \multicolumn{5}{|c|}{ Bale Factor $^{1}$} & \\
\hline & TU & IA & VL & QH & ET & Overall \\
\hline Pearson's $r^{2}$ & .993 & .980 & .988 & .998 & 1.000 & .974 \\
\hline
\end{tabular}

${ }^{1} \mathrm{TU}=$ teaching for understanding; $\mathrm{IA}=$ instructional approach; $\mathrm{VL}=$ valuing the learner as an individual; $\mathrm{QH}=$ questioning habits; $\mathrm{ET}=$ extension of students' thinking; for each factor d.f. $=6, \mathrm{p}<.01$; overall d.f. $=38, \mathrm{p}<.01$ 


\subsection{Unfacilitated Versus Facilitated Administration}

Scores obtained on the unfacilitated and facilitated administration of the BALE are summarized in Table 2. Unfacilitated administration of the BALE consisted of providing the new and continuing groups of preservice teachers with a sheet of paper that provided the writing prompt, directions, and space to write their ideas. Participants in each group were told to work together to construct an answer they felt fully addressed the prompt, that their conversation would be recorded, and that they could take as much time as they needed. With the unfacilitated administration, both the continuing participants and the new participants received an overall score of 21.5 out of 60 possible points, or $35.8 \%$. Thus, although the continuing preservice teachers had one semester more teaching experience than the new preservice teachers (student teaching plus) and a full year of professional development using constructivist, inquiry-based learning strategies, their score on the unfacilitated administration of the BALE was identical to that of the new participants.

Table 2. BALE subscores and totals of continuing participants and new participants for unfacilitated and facilitated administrations of the BALE instrument.

\begin{tabular}{l|c|c|c|c|c|c|c|c|c|c|c|c}
\hline & \multicolumn{3}{|c|}{$\begin{array}{c}\text { Continuing } \\
\text { Factor }\end{array}$} & \multicolumn{4}{|c|}{$\begin{array}{c}\text { New } \\
\text { Unfacilitated }\end{array}$} & \multicolumn{3}{c|}{ Unfacilitated $^{2}$} & \multicolumn{4}{c}{$\begin{array}{c}\text { New } \\
\text { Continuing Facilitated }\end{array}$} & \multicolumn{4}{c}{ Facilitated $^{2}$} \\
\hline & S1 & S2 & $\mathrm{M}$ & $\mathrm{S} 1$ & $\mathrm{~S} 2$ & $\mathrm{M}$ & $\mathrm{S} 1$ & $\mathrm{~S} 2$ & $\mathrm{M}$ & $\mathrm{S} 1$ & $\mathrm{~S} 2$ & $\mathrm{M}$ \\
\hline $\mathrm{TU}$ & 8 & 9 & 8.5 & 9 & 9 & 9 & 18 & 18 & 18 & 18 & 17 & 17.5 \\
\hline $\mathrm{IA}$ & 7 & 8 & 7.5 & 6 & 5 & 5.5 & 15 & 15 & 15 & 11 & 12 & 11.5 \\
\hline $\mathrm{VL}$ & 4 & 3 & 3.5 & 4 & 4 & 4.5 & 7 & 7 & 7 & 8 & 8 & 8 \\
\hline $\mathrm{QH}$ & 1 & 1 & 1 & 2 & 2 & 2 & 4 & 5 & 4.5 & 4 & 5 & 4.5 \\
\hline ET & 1 & 1 & 1 & 1 & 1 & 1 & 2 & 3 & 2.5 & 1 & 1 & 1 \\
\hline Total & 21 & 22 & $\mathbf{2 1 . 5}$ & 22 & 21 & $\mathbf{2 1 . 5}$ & 46 & 48 & $\mathbf{4 7}$ & 42 & 43 & $\mathbf{4 2 . 5}$ \\
\hline
\end{tabular}

${ }^{1} \mathrm{TU}=$ teaching for understanding; $\mathrm{IA}=$ instructional approach; $\mathrm{VL}=$ valuing the learner as an individual; $\mathrm{QH}=$ questioning habits; ET = extension of students' thinking

${ }^{2} \mathrm{~S} 1=$ scorer $1 ; \mathrm{S} 2=$ scorer $2 ; \mathrm{M}=$ mean

For the facilitated administration, each group was led in a discussion by a researcher and told that their conversation would be recorded. The same prompt that was given during the unfacilitated administration was asked and the participants were encouraged to again respond until they felt they had fully answered the question. The discussion leader then asked a series of probing questions based on the 12 characteristics describing the five factors upon which the BALE rubric is organized. With the facilitated administration, the continuing group earned an overall score of 47 out of 69 points $(78.3 \%)$ and the new group had an overall score of 42.5 out of 60 points $(70.8 \%)$. Thus, both groups at least doubled their score with the facilitated administration. In addition, the continuing group of preservice teachers, which had completed student teaching and a full year of professional development using constructivist, inquiry-based learning strategies, scored 4.5 points, or $7.5 \%$, higher than the new group of preservice teachers who had yet to begin student teaching and had experienced only 1.5 days of professional development.

\section{$5 \quad$ Discussion and Conclusion}

This study compared the effectiveness of an unfacilitated administration to a facilitated administration of the Beliefs About the Learning Environment (BALE) instrument to measure the constructivist beliefs of two groups of preservice teachers. In the unfacilitated approach, both groups of preservice teachers were given a sheet of paper with a writing prompt and directed to work collaboratively to address the prompt as completely as possible. The audio recorded responses were coded and scored using the BALE rubric. In the facilitated approach, both groups of preservice teachers participated in a discussion facilitated by a researcher who provided specific prompts to guide the participants' thinking toward the 
five factors of effective constructivist teaching identified in the BALE rubric. These conversations were also recorded, coded, and scored.

Results of the study indicated that the facilitated administration yielded higher scores than the unfacilitated administration in both groups of preservice teachers. Furthermore, the facilitated administration was able to discriminate between the continuing group of preservice teachers who had completed one year of professional development using constructivist learning strategies, as well as student teaching, and the new group of preservice teachers who had completed just 1.5 days of professional development and had not yet begun student teaching. The results also support Berliner's stage theory of teacher development and underscore the validity of the BALE instrument's factors and belief characteristics.

Underlying the findings in this study is the notion that "we know more than we can tell" (Polanyi, 1967). Teachers possess knowledge about teaching and learning that is used on a daily basis, but may be difficult to articulate. This tacit knowledge (Sternberg, 1999) is practically useful, and teachers may effectively apply it in the classroom without being aware they are doing so. This leads us to an important question: If teachers can appropriately and effectively use knowledge in the classroom, but cannot make their knowledge explicit (e.g., in a verbal report), what can we say the teacher "knows"? The answer to this question is both philosophical and empirical, and can be explored within several methodological approaches. But if teachers do not demonstrate their knowledge within one methodological approach, does that mean they do not possess the knowledge at all? The findings from this study demonstrated that when specifically prompted, pre-service teachers could articulate their knowledge far better than when the prompt was broad and general.

The findings nicely parallel a line of reasoning about the methodological shortcomings of Lawrence Kohlberg's cognitive developmental theory (Shweder, Mahapatra \& Miller, 1987). The typical methodological approach for measuring moral reasoning was to ask subjects to respond to a moral dilemma such as the well-known Hienz dilemma, in which Hienz must decide whether or not to steal a life-saving cancer drug from a greedy druggist in order to save his wife's life. Subjects would be asked to decide what Heinz should do, and then explain their decision. Researchers would analyze the subjects' decision to determine their stage of moral development. Higher stages of moral development are historically difficult to detect using the moral dilemma interview methodology. Shweder et al. (1987) argue, "most people do not have good verbal access to their own available concepts or intellectual processes" (p.16), and therefore are unable to effectively articulate sophisticated moral arguments. A similar argument can be made for BALE respondents who are asked to respond to one general prompt.

The changes made in this study in the measurement of pre-service teachers' beliefs mirror the methodological changes in the study of moral reasoning. Instead of asking people to respond to one open question, Turiel and colleagues (e.g., Turiel, 1983) allowed subjects to respond to a series of direct probes. The results of these direct probe interviews suggested that people (specifically children) were more capable of understanding "higher" moral concepts than what would be revealed in a standard Kohlbergian interview. Shweder et al. (1987) suggested, "more directed probes may be needed to get at their implicit understandings". Their suggestion, it turns out, was also appropriate for the measurement of teachers' beliefs about effective learning environments. This study revealed that several more directed probes were more effective at uncovering teachers' constructivist beliefs than one general probe.

A significant implication of this study is that with proper development teachers can modify their knowledge of and beliefs about inquiry science teaching over time; however, we cannot expect to measure change accurately simply by asking preservice or inservice teachers to express their understanding and beliefs through the use of a general discussion prompt. Teaching is a complex practice for which individual considerations become automatic (Schneider \& Chein, 2003) and subliminal, much like an experienced driver becomes unaware of the many decisions and actions required to negotiate heavy traffic. Rather, measuring this change requires the use of a more structured approach that stimulates thinking about aspects of teaching that are critical but often addressed by teachers without their awareness. The facilitated administration of the BALE instrument has been shown to be an effective strategy to measure pre-service teachers' (and presumably inservice teachers') thinking about inquire-based science teaching.

Future research with the BALE instrument will examine the effects of professional development on the beliefs of both preservice teachers and inservice teachers. To increase sample size, the BALE will be administered orally to individual preservice teachers and inservice teachers. Individual and group 
administration of the BALE will explore differences in the socially-constructed beliefs of a focus group versus the beliefs of individuals who make up the focus group.

\section{$6 \quad$ Limitations}

Three factors may have affected the results of the study. First, participant responses to the BALE prompt were not scored using a blind review process. That is, the scorers knew the group and type of administration that produced each transcript; however, one of the two scorers was not part of the professional development team and was unfamiliar with the purpose of the research study prior to coding and scoring the responses. The very high interrater agreement suggests that any bias introduced by the scorer with knowledge of the research project was negligible. Second, the interviews were conducted by two different members of the research team. There were no checks to ameliorate this potential source of bias except that both interviewers were experienced and cognizant of ethical interview protocols. Finally, the sample size was too small to enable a valid statistical analysis to determine if differences between the administrative strategies and the participant groups were significant.

Acknowledgements. This project was funded by a grant to support NWO-TEAMS from the Ohio Department of Education. We thank Rachel Chervenak for her assistance with data analysis and the Center of Excellence in Science and Mathematics (COSMOS) at Bowling Green State University for support on this project. We also thank the preservice teachers who agreed to participate in the study and commit themselves to a year of professional development.

\section{References}

1. R. M. Allen and R. M. Caspergue (1997), "Evolution of novice through expert teacher's recall: Implications for effective reflection on practice," Teaching and teacher education, vol. 13, no. 7, pp. 741-755.

2. A. Bandura (1997), Self-efficacy: The exercise of control. W. H. Freeman.

3. D. Berliner (1988), The development of expertise in pedagogy. American Association of Colleges of Teacher Education.

4. C. M. Czerniak and A. T. Lumpe (1996), "Relationship between teacher beliefs and science education reform," Journal of science teacher education, vol. 7, no. 4, pp. 247-266.

5. B. Crawford (2007), "Learning to teach science as inquiry in the rough and tumble of practice," Journal of research in science teaching, vol. 44, no. 4, pp. 613-642.

6. H. L. Dreyfus and S. E. Dreyfu (1986), Mind over machine. The Free Press.

7. J. J. Haney, C. M. Czerniak, and A. T. Lumpe (1996), "Teachers' beliefs and intentions regarding the implementation of science education reform strands," Journal of Research in Science Teaching, vol. 33, pp. 971993.

8. J. J. Haney, A. T. Lumpe, and C. M. Czerniak (2003), "Constructivist beliefs about the science classroom learning environment: Perspectives from teachers, administrators, parents, community members, and students." School science and mathematics, vol. 103, no. 8, pp. 366-377.

9. J. Hattie (2002), "What are the attributes of excellent teachers?" In B. Webber (Ed.), Teachers make a difference: What is the research evidence? pp. 3-26, New Zealand Council for Educational Research.

10.J. M. LeBreton and J. L. Senter (2008), "Answers to 20 questions about interrater reliability and interrater agreement," Organizational research methods, vol. 11, no. 4, pp. 815-852.

11.A. T. Lumpe, J. J. Haney, and C. M. Czerniak (1998), "Science teacher beliefs and intentions to implement science-technology-society (STS) in the classroom," Journal of science teacher education, vol. 9, no. 1, pp. 1-24.

12.A. T. Lumpe, J. J. Haney, and C. M. Czerniak (2000), "Assessing teachers' beliefs about their science teaching context," Journal of research in science teaching, vol. 37, no. 3, pp. 275-292.

13.National Research Council (2012), A framework for K-12 science education: Practices, crosscutting concepts, and core ideas. National Academies Press.

14.National Science Teachers Association (2013), Position statement: The Next Generation Science Standards. Available: www.nsta.org/about/positions/ngss.aspx 
15.NGSS Lead States (2013), Next generation science standards: For states, by states. National Academies Press.

16.J. E. Ormrod (2003), Educational psychology: Developing learners (4th ed.). Pearson Education.

17.M. F. Pajares (1992), "Teachers' beliefs and educational research: Cleaning up a messy construct," Review of educational research, vol. 62 , no. 3, pp. 307-332.

18.D. J. Palmer, L. M. Stough, and T. K. Burdenski, Jr (2005), "Identifying teacher expertise: An examination of researchers' decision making," Educational psychologist, vol. 40, no. 1, pp. 13-25.

19.M. Polanyi (1967), The tacit dimension. Anchor Books.

20.R. A. Shweder, M. Mahapatra, and J. G. Miller (1987), "Culture and moral development," In J. Kagan and S. Lamb (Eds.), The emergence of morality in young children, pp. 1-83. University of Chicago Press.

21.W. Schneider and J. M. Chein (2003), "Controlled and automatic processing: Behavior, theory and biological mechanisms," Cognitive psychology, vol. 27, no. 3, pp. 525-559.

22.R. Sternberg (1999), "What do we know about tacit knowledge? Making the tacit become explicit," In R. Sternberg and J. Horvath (Eds.), Tacit knowledge in professional practice: Researcher and practitioner perspectives, pp. 231-236. Lawrence Erlbaum and Associates.

23.E. Turiel (1983), The development of social knowledge: Morality and convention. Cambridge University Press.

24.G. F. Varrella (1997), The relationship of science teachers' beliefs and practices. (Doctoral Dissertation). Available: UMI Microform. (UMI9805730)

25.G. F. Varrella and J. Burry-Stock (1997) "The application of a rubric to assess constructivist beliefs among teachers in the Iowa scope, sequence, and coordination project," A paper presented at the Association for the Education of Teachers in Science Annual Meeting, Cincinnati, OH.

26.E. A. Worch, J. L. Pollock, E. Duran, and J. N. Burgoon (2009), "The impact of sustained professional development on preservice teachers' concept of an effective learning environment," National social science proceedings, vol. 41, no. 3, pp. 227-241. 